\title{
OECLASSIFIED
}

\author{
AECD -3344 \\ HW-22765 \\ Chemistry - General
}

\section{THE COULOMETRIC DETERMINATION OF URANIUM}

By

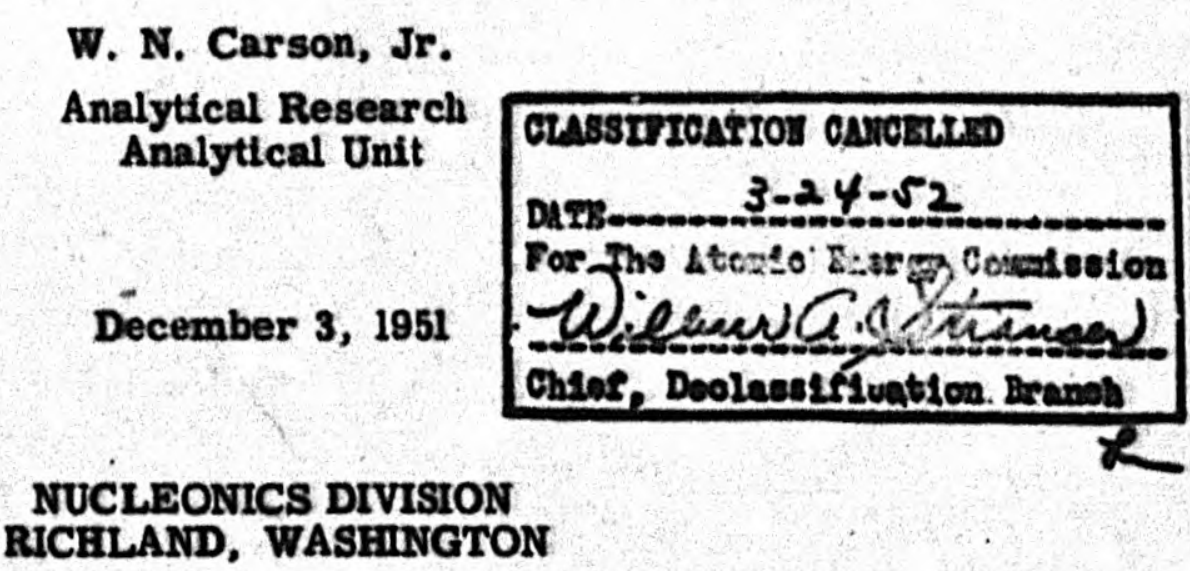

Operated for the Atomic Energy Commission by the General Electric Company under Contract W-31-109-Eng-52 


\section{THE COULOMETRIC DETERMINATION OF URANIUM}

\section{INTRODUCTION}

The determination of uranium by titration is usually accomplished by the oxidation or reduction to the six or four valence state of the element. Of the several redox methods, one of the more useful is the oxidation of uranium(IV) to uranium(VI) by ferric ion. This method has been described by Shipley (8). It consists of pretreating the sample to remove or nullify interferences, reducing the uranium to a mixture of the $U$ (III) and $U$ (IV) valence states by means of a Jones reductor, and titrating with standard ferric sulfate solution back to $U(V I)$ at an elevated temperature.

A study was made to adapt this method to a microcoulometric method. Many modifications were found necessary, but the basic titration scheme of preliminary reduction of the uranium followed by oxidation with ferric lon proved feastble and was retained. The method proved readily adaptable for use on an automatic titrator reported previously (1).

\section{SUMMARY}

An automatic coulometric titration has been developed. The method uses the automatic titrator described previously and depends upon the use of a lead reductor to reduce the uranium to the (IV) valence state, and electrolytically generated bromine in the presence of iron to oxidize the uranium to the (VI) valence state. Samples of 0.01 to

$7 \mathrm{mg}$. uranium content can be automatically titrated. The interferences with the method are few, and dilutions of $10^{-5} \mathrm{M}$ uranium can be titrated.

\section{EQUIPMENT}

The constructional details of the titration cell used in manual and automatic titrations are given in Figure 1. The indicator system is that of Relley, Cooke, and Furman (6). The electrodes are two platinum 
wires dipping in the sample. These are polarized by a small constant current of 1.1 to 1.3 microamperes, as explained by Rellley, et. al. (6). The constant current source is composed of several 45 volt "B" batteries (Burgess Z3ONX) connected in parallel with 40 megohms resistance in series.

The generator system is a two compartment cell composed of a platinum anode immersed in the sample solution contained in one compartment, and a platinum cathode immersed in $1: 1$ sulfuric acid in the other compartment, the two compartments connected by means of a silica gel salt bridge. The salt bridge is prepared by filling a tube to the required length with sodium silicate solution $\left(40^{\circ} \mathrm{Be}\right)$. The tube is immersed in 1:1 sulfuric acid, and 1:1 sulfuric acid is placed on top of the solution. The acid causes a thin film of gel to form immediately which seals in the solution. The bridge can be used after a short (15 min.) aging period. Diffusion of acid from the catholyte causes all of the solution to gel in a few days to a compact, low resistance plug. If made properly, the bridge permits only a very small flow of catholyte, and remains operative under the heat and acid conditions of the titration with a life under continuous use of several months. The catholyte must be replenished from time to time with 1:1 sulfuric acid.

The cell is heated by a small heating element (Hotspotter Heating Element, Fisher Scientific Co., Cat. No. 11-502-15) controlled by a simplytrol pyrometer (Cat. No. 4533, Assembly Products Co., Chagrin Falls, Ohio), which uses the iron-constantan thermocouple for temperature sensing. A 100-ohm 100 watt resistance is placed in series with the heater circuit to permit slower heating and extend the heater life. The temperature of titration is $95 \pm 1^{\circ} \mathrm{C}$ and is critical. Above this temperature the solution boils and ruins the determination. Below $92^{\circ}$ the titration reactions are too slow for automatic titrator use, and below $90^{\circ}$ are too slow for manual use. The condenser of the cell returns water evaporated by the sweep gas from the sample. 
If it is not used, the evaporative losses are very large, and the sample cannot be titrated for more than a few minutes. Rapid stirring of the sample is necessary but is not critical. The gas blanket used to prevent air oxidation is carbon dioxide, but nitrogen or other inert gas could be used. The carbon dloxide is freed of oxygen by use of the gas scrubbing train shown in Figure 2. The gas is passed through water, chromous sulfate, and water again. The first water scrubber is used to saturate the gas to lessen the evaporative loss in the chromous sulfate scrubbers, the second is to remove chromous sulfate spray. The first chromous sulfate scrubber is a modification of a gas scrubber described by Shaw(7). The action is as follows: the incoming gas passes through the jet and pulls or traps a small amount of solution into the center tube. This is forced up the top of the scrubber by the gas, and splashes back on the glass beads in the top of the scrubber. The large surface exposed to the gas gives very efficient scrubbing. The liquid drains back to the reservoir at the bottom of the scrubber, where it passes through amalgamated zinc to reduce any oxidized chromium. The solution used is $15 \mathrm{~g}$. 11 . chromic sulfate in $1: 4$ sulfuric acid and is replenished by additions from the reservoir. The second scrubber is used as an indicator of failure of operation of the first, since small amounts of oxygen cause a marked change from blue to green in the color of the solutin. A flow rate of approximately $100 \mathrm{cc}$. $/ \mathrm{min}$. per titration cell is necessary.

The manual titration apparatus is shown as a block diagram in Figure 3. The constant current source can be any suitable source; the one used has been described by Carson and Ko (2). The timer is a Standard Electric Time Company Model SM 60 electric stopwatch, used as described previously. The potentiometer is a Leeds and Northrup No. 7655 portable potentiometer; any good student type potentiometer can be used. The indicator system requires a high impedance volt meter; a Beckman Model G or Model H-2 pH meter is satisfactory. The automatic titration equipment has been described in a previous report (1). 


\section{TITRATION CHEMISTRY}

Reactions. The following equations give the reactions occurring during the analysis:

Reduction of sample in lead column:

1) $\mathrm{UO}_{2} \mathrm{Br}_{2}+4 \mathrm{HBr}+\mathrm{Pb} \longrightarrow \mathrm{UBr}_{4}+\mathrm{PbBr}_{2}+2 \mathrm{H}_{2} \mathrm{O}$

2) $2 \mathrm{FeBr}_{3}+\mathrm{Pb} \longrightarrow 2 \mathrm{FeBr}_{2}+\mathrm{PbBr}_{2}$

Electrolysis:

3) (at cathode) $2 \mathrm{H}^{+}+2 \mathrm{e} \longrightarrow \mathrm{H}_{2}$

4) (at anode) $2 \mathrm{Br}^{-}-2 \mathrm{2e} \longrightarrow \mathrm{Br}_{2}$

Oxidation of sample in titration cell at $95^{\circ} \mathrm{C}$

5) (Fast) $2 \mathrm{FeBr}_{2}+\mathrm{Br}_{2} \longrightarrow 2 \mathrm{FeBr}_{3}$

6) (Slow) $2 \mathrm{FeBr}_{3}+\mathrm{UBr}_{4}+2 \mathrm{H}_{2} \mathrm{O} \longrightarrow \mathrm{UO}_{2} \mathrm{Br}_{2}+4 \mathrm{HBr}+$ $2 \mathrm{FeBr}_{2}$

Reactions 1 and 2 require the presence of a minimum of $3 \mathrm{M}$ chloride or bromide. The reduction is rapid and quantitative in either case. Chloride is unsuitable for the titrations since poorly defined endpoints are obtained. The presence of chloride in the titration does not interfere, however, when a bromide media is used. The primary anode reaction product is not accurately known, although a reasonable process is the evolution of free bromine as shown. It is possible that the iron is directly oxidized, but not very probable. Iron must be present for the oxidation to be stolchiometric with respect to uranium. The controlling reaction rate is the relatively slow reaction between ferric ion and the uranium(IV). This rate is too slow for practical titrations unless the temperature is kept above $90^{\circ} \mathrm{C}$.

Interferences. A number of interferences of the titration exist, but many can be easily removed by simple treatment. Molecular

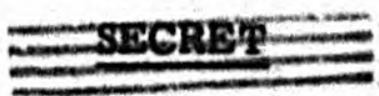


oxygen rapidly oxidizes the hot ruduced solution and must be exluded by blanketing the titration vessel with an inert gas. Dissolved oxygen in the reagent solutions causes significant errors in the titration of 10-500 microgram quantities of uranium, although this error is negligible for larger amounts of uranium. For low levels the solutions are bolled to free them of dissolved oxygen prior to use. A resume of the study made on interferences is given in Table $I$. The tests were made as follows: for each element, a large excess of test reagant (50-100 times the molar equivalent of uranium) was added as a solution of the compound listed in the table to $2 \mathrm{mg}$. samples of uranium. Concentrated hydrobromic acid was added, and the sample solutions bolled down to expel any volatile reaction products. The solution was diluted with dilute . hydrobromic acid, reduced in the usual manner, and titrated. For elements listed as "no interference", this first sample did not change the titre of the standard sample. Several checks were made on each element at the high level if it did not give an interference. For interfering elements, lesser amounts were tried to find the maximum amount that could be tolerated. Of the interfering elements, only chromium and phosphate can be tolerated in amounts greater than traces. In the case of chromium, the interference is removed by pretitration; in the case of phosphate no interference is observed up to a 30:1 mole ratio ( phosphate to uranium). Above this ratio, the precision of titration decreasus; above $50: 1$ there is a marked interference giving erratic results.

Of the elements not listed, the rare earths, alkaline earths, and allcalis will not interfere; possibillties are some of the platinum metals, tantalum, tellurium, thorium, and niobium.

lodine interferes in a unique manner by depolarizing the indicator electrodes whether present as iodide or free iodine. Any generated free Iodine should oxidize iron at the elevated temperature, similarly to free bromine, and so not interfere with the titration reaction, but both poliarized and potentiometric indicator electrodes are unusable in its presence. 
TABLE I

\section{RESUME OF INTERFERENCE STUDIES ON TITRATION OF URANIUM}

Element

Aluminum

Antimony

Arsenic

Boron

Calcium

Chlorine

Chromium

Cobalt

Copper

Fluorine

Gold

Iodine

Magnesium

Manganese

Mercury

Molybdenum

Nickel

Nitrogen

Palladium

Phosphorus

Plattaum

silicon

Sulfur
Added as

$\mathrm{AlCl}_{3}$

$\mathrm{Na}_{3} \mathrm{SbO}_{4}$

$\mathrm{Na}_{3} \mathrm{AsO}_{4}$

$\mathrm{HBO}_{3}$

$\mathrm{CaCl}_{3}$

$\mathrm{HCl}$

$\mathrm{N}_{2} \mathrm{Cr}_{2} \mathrm{O}_{7}$

$\mathrm{CoCl}_{2}$

$\mathrm{CuSO}_{4}$

$\mathrm{NaF}$

$\mathrm{AuCl}_{3}$

KI

$\mathrm{MgCl}_{2}$

$\mathrm{IMnO}_{4}$

$\mathrm{HgCl}_{2}$

$\mathrm{Na}_{2} \mathrm{MoO}_{4}$

$\mathrm{NiCl}_{2}$

$\mathrm{HNO}_{3}$

$\mathrm{PdCl}_{2}$

$\mathrm{NaH}_{2} \mathrm{PO}_{4}$

$\mathrm{H}_{2} \mathrm{PtCl}_{6}$

$\mathrm{Na}_{2} \mathrm{SiO}_{3}$

$\mathrm{Na}_{2} \mathrm{SO}_{4}$
Remarks

Does not interfere

Non-stoichiometric interference, not pretitratable

Non-stoichiometric interference, not pretitratable

Does not interfere

Does not interfere

Does not interfere

Non-stoichiometric interference, pretitratable

Does not interfere

Does not interfere

Non-stoichiometric interference, removed by complexing with $\mathrm{Zr}$ or $\mathrm{B}$

Does not interfere

Renders indicator system used inoperative

Does not interfere

Does not interfere

Does not interfere

Non-stoichiometric interference, not pretitratable

Does not interfere

Does not interfere

Dous not interfere

Does not interfere up to $30: 1$ mole ratio $\mathrm{PO}_{4}: \mathrm{U}$

Non-stoichiometric interference, not pretitratable

Does not interfere

Does not interfere 
TABLE I (Cont.)

\begin{tabular}{|c|c|c|}
\hline Element & Added as & Remarks \\
\hline Tin & $\mathrm{SnCl}_{4}$ & $\begin{array}{l}\text { Non-stoichiometric interference, not } \\
\text { pretitratable }\end{array}$ \\
\hline Titanium & $\mathrm{TiCl}_{3}$ & $\begin{array}{l}\text { Non-stoichiometric interference, not } \\
\text { pretitratable }\end{array}$ \\
\hline Tungsten & $\mathrm{Na}_{2} \mathrm{WO}_{4}$ & $\begin{array}{l}\text { Stoichiometric interference, not } \\
\text { pretitratable }\end{array}$ \\
\hline Vanadium & $\mathrm{NaVO}_{3}$ & $\begin{array}{l}\text { Non-stoichiometric interference, not } \\
\text { pretitratable }\end{array}$ \\
\hline Zine & & Does not interfere \\
\hline Zirconium & $\mathrm{ZrOCl}_{2}$ & Does not interfere \\
\hline Formate & HCOOH & $\begin{array}{l}\text { Interferes, removed by oxidation with } \\
\text { bromine prior to reduction }\end{array}$ \\
\hline Oxalate & $\mathrm{Na}_{2} \mathrm{C}_{2} \mathrm{O}_{4}$ & $\begin{array}{l}\text { Interferes, removed by oxidation with } \\
\text { bromine prior to reduction }\end{array}$ \\
\hline Sulfide & $\mathrm{Na}_{2} \mathrm{~S}$ & $\begin{array}{l}\text { Interferes, removed by oxidation with } \\
\text { br omine prior to reduction }\end{array}$ \\
\hline Sulfite & $\mathrm{Na}_{2} \mathrm{SO}_{3}$ & $\begin{array}{l}\text { Interferes, removed by oxidation with } \\
\text { bromine prior to reduction }\end{array}$ \\
\hline $\begin{array}{l}\mathrm{NH}_{3} \\
\text { Sulfamate }\end{array}$ & $\begin{array}{l}\mathrm{NH}_{4} \mathrm{Cl} \\
\mathrm{FSO}_{3} \mathrm{NH}_{2}\end{array}$ & $\begin{array}{l}\text { Does not interfere } \\
\text { Does not interfere }\end{array}$ \\
\hline
\end{tabular}

The reagents used in the titration often contain significant amounts of impurities. In one case it was found the vendor's hydrobromic acid contained $0.5 \mathrm{mg}$. per liter of uranium. This level of impurity is signiflcant because of the large amount of acid (compared to the sample) used in the determination. The iron bromide solution is a source of interference occasionally; this is best prepared by dissoiving pure iron in hydrobromic acid, using free bromine to hasten the dissolution. 


\section{PROCEDURE}

\section{Reagents Used in Titration}

Test Lead: C. P. granules, silver and bismuth-free.

Fydrobromic Acid: concentrated, C. P. $48 \%$.

Electrolytic Iron: Standard Sample Company, Ames, Iowa, hydrogen fired standard electrolytic iron.

1 M Iron Bromide: Dissolve $55 \mathrm{~g}$. of electrolytic iron in $500 \mathrm{ml}$. hydrobromic acid, add bromine to hasten dissolution, and dilute to 1 liter after the iron is dissolved.

Iron Rinse Solution: $0.02 \mathrm{M}$ iron and $3 \mathrm{M} \mathrm{HBr}$. Add $336 \mathrm{ml}$. concent $\bar{r}$ ated $\mathrm{HBr}$ to $20 \mathrm{ml}$. $1 \mathrm{M}$ iron bromide solution and dilute to $T$ liter. Boll gently for 5 minutes just before use under a blanket of oxygen-Free Thert gas, If less than $\mathbf{5 0 0}$ microgram samples of uranium are used.

Sample Size. Samples containing 5 micrograms to approximately $7 \mathrm{mg}$. of uranium can be titrated by the manual titration; the lower limit of the automatic procedure is approximately 10 micrograms. The precision of the manual titration is better than that of the automatic titration for samples with less than 50 micrograms, and is poorer for samples with more than 200 micrograms.

Due to the limitation on volume in the tistration cell and the difflculty in rinsing the lead reductor where large sample volumes are used, the maximum sample volume is approximately $2 \mathrm{ml}$. The volume applies to the pretreated sample volume; 1.e. , the sample after adjustment to a $3 \mathrm{MBr}$ content. Any size sample volume can be used if it can be adjusted to this volume prior to reduction.

Pretreatment. The preparation of the sample for reduction conststs of removing interferences and adjusting to $3 \mathrm{M} \mathrm{HBr}$ content. For samples containing no interferences, the treatment consits of adding concentrated hydrobromic acid until the sample is $3 \mathrm{M}$ HBr. The only limitation is that the final volume must be a maximum of approx. $2 \mathrm{ml}$.

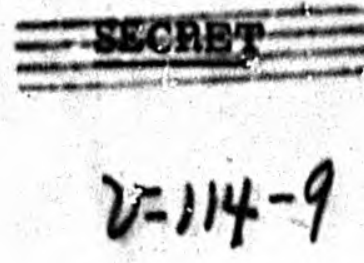


for the fitration celf design given here. For samples containing nitrate, dichromate, permanganate, and other easily reduced interferences, the sample is bolled with concentrated hydrobromic acid until the bromide formed is expelled. For samples containing reducing interferences, the solution is heated with hydrobromic acid and bromine. Most of the axcess bromine should be removed by bolling for a fow minutes prior to reduction.

The treatment for interferences that are not removed by the simple methods given above has not been studied in detail except for fuoride. Fluoride is removed as an interference by complexing with zirconium. Methods are described by Shipley (o) for removal of some of the listed interferences.

Manual Titration. Take the required sample and pretreat so remove interferences. Outgas the titration cell thoroughly with a rapid stream of inert gas. Transfer the sample quantitatively to the top of the lead reductor, and pass it through the reductor at a rate of approximately $5 \mathrm{mil}$. $/ \mathrm{min}$. Rinse the sample vessel three times with $2-3$ $m i$. portions of iron rinse salution, and pass rinses through the reductor, allowing the reductor to drain to the top of the lead between each rinse. Turn on the heater and stirrer after the first rinse has been added. Risse the column once with a $3 \mathrm{kl}$. pertion of ir on rinse solution. The final volume in the titration cell should be $12-15 \mathrm{ml}$, Allow the sample to heat to $95^{\circ} \mathrm{C}$ and start the olestrolysis by elosiag the "titrate" switci on the constant current source. Continue the electrolysis until the voltage across the indisator electrodes is $200 \mathrm{mv}$. From this point, titrate in 5 second or 0.1 minute increments. The Indicator systein should be allowed to reach equllibrium between incre. ments of electrolysis. Comput the endpoint location by the interpolation formula given previously (2).

The above procedure needs a slight mo Iftcation with samples of low uranlumi content. With samples expinining less than $0.5 \mathrm{mg}$. of

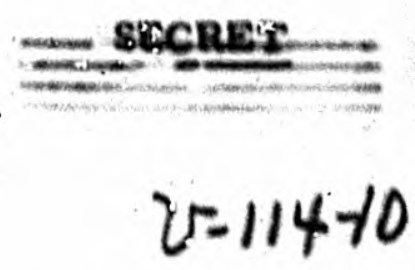


uranium, the iron rinse solution must be boiled for a few minutes before use to expel oxygen.

Automatic Titration Procedure. This procedure refers to the use of the automatic titrator described previously (1). Set the control of the titrator as follows:

Constant current at factor current desired pH meter to 0-800 mv., and standardize Trigger at $175 \mathrm{mv}$.

Time of endpoint duration at 30 seconds Pyrometer contact at $95^{\circ} \mathrm{C}$.

Prepare the sample and introduce it into the titration cell in the same manner as for the manual titration. Turn the "titrate" switch to "On". The titrator will now heat the sample to the titration temperature, titrate it to the endpoint, and turn itself off. The titration is complete when the "Timed Out" pilot turns on. Remove the titrated sample and rinse the cell thoroughly. Record the time and turn the titrate switch to "Reset". The titrator is now ready for the next sample.

Computations. The numbers of milliequivalents of uranium are computed by multiplying the current in milliamperes by the time in seconds and dividing by 96,500 . This divided by two gives the number of millimoles of uranium in the sample. For samples with less than $1 \mathrm{mg}$. of uranium, a blank correction is necessary. This is determined by manual titration at low currents with the same amount of electrolyte used in the analysis and represents the time necessary to generate sufficient ferric ion to give an endpoint. It is inversely proportional to the current and can be calculated for any current, once it is known for a particular current. The use of factor currents, especially for the automatic titrator, is recommended for routine use. With their use, the operator needs only to multiply the time of titration by the factor $Q$ to obtain the result. By a proper choice of $Q$, this multiplication can be made very simple. In order to compute the current necessary to 
give the factor $Q$, the following formula can be used:

$$
i=\frac{F \times Q \times S}{b \times M \times 10^{6}}
$$

where 1 = current in milliamperes to give the factor $\mathbf{Q}$

$$
\begin{aligned}
& \mathbf{F}=\text { Faraday } \\
& \mathbf{S}=\text { Sample size in microliters } \\
& \mathbf{b}=\text { Unit time in seconds } \\
& \mathbf{M}=\text { Milliquivalent weight of compound } \\
& \mathbf{Q}=\text { Factor (G./1. per unit time) }
\end{aligned}
$$

Thus, the factor current making 1 minute (the unit time) of titration time equivalent to $100 \mathrm{~g}$. $/ 1$. uranium is computed as follows:

$$
\begin{aligned}
Q & =100 \\
b & =60 \\
M & =\frac{U}{2000}=\frac{238.07}{2000} \\
\cdot i & =\frac{96,500 \times 100 \times 2000 \times S}{60 \times 238.07 \times 10^{6}} \\
& =2.3515 \mathrm{ma} .
\end{aligned}
$$

Using the current computed in this fashion, the uranium content in g. $/ 1$. of a sample would be $100 \times t$, where $t$ is given in minutes. A titration time of $1.345 \mathrm{~min}$. would be equivalent to $134.5 \mathrm{~g}$. $/ 1$. uranium in the sample. Other compounds of uranium could be reported if the milliequivalent weight of the compound is used in place of the $\frac{U}{2000}$ value of this example.

\section{RESULTS}

Titration of Uranium Standard. A standard solution of uranyl bromide was prepared by dissolving metallic uranium in hydrobromic acid and oxidizing the uranium to the (VI) oxidation state with bromine. The solution was made up to contain $278.9 \mathrm{~g}$. $/ 1$. uranium. Dilutions of 1000:1, 100:1, and 10:1 were made, and microaliquots were taken to give the samples shown in Table II. Ten aliquots of each sample size were

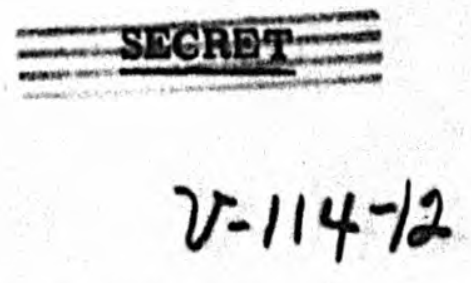




\section{Tumas $n$}

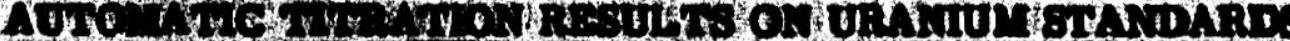

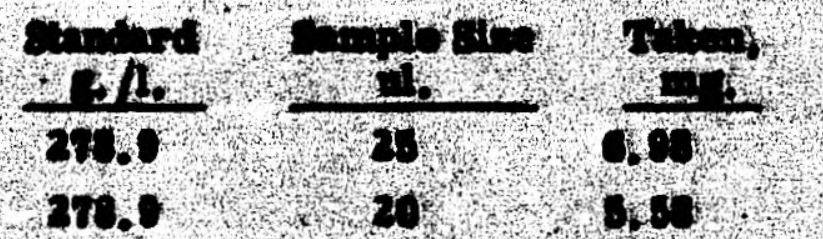

27. 0

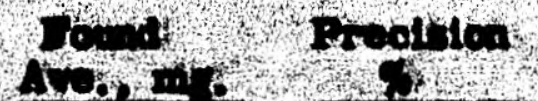

Awo. Titration

then min.

$020+0.20$

0,45

Brolly,

Gurvunt:

5.60 \% $\quad \pm 0.31$

780

0

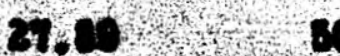

2.00

$\pm 0,16$

6. 48

8:102

0

7.00 : 20

$1 \times 10^{2}$

4

$\pm 0$.

3.00

0.020

2,20

0,278

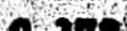

$+0,0$

$380 \mathrm{a}$

0.050

0.100

$0.10 \mathrm{x}$

$\pm 2.8$

0.035

180

$30 \%$

$40 \mathrm{~d}$

0.128

0.500

0.800

0,250

0,020

0.01980

$\pm 0,0$

2. 403

0.800
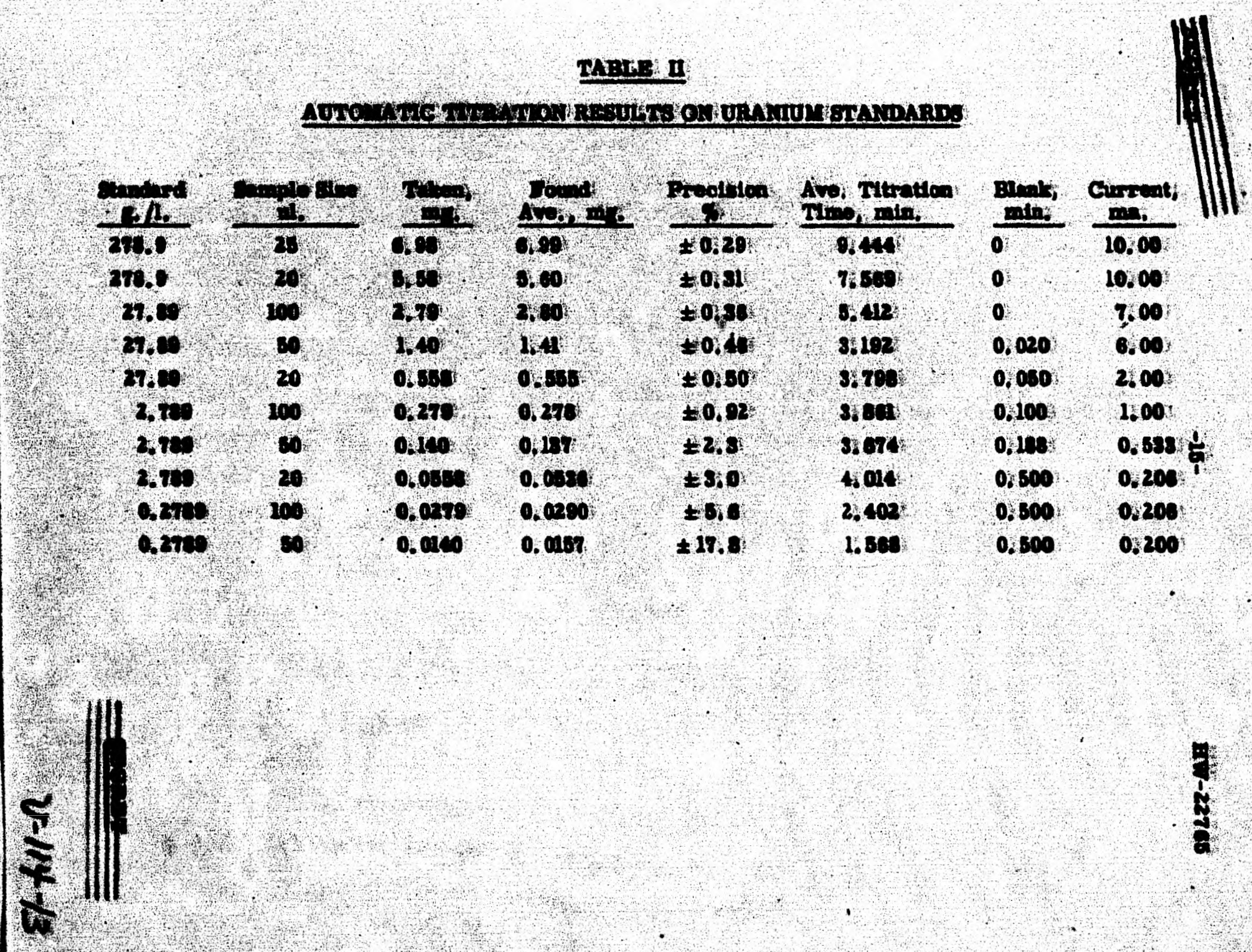
analyzed by the automatic titrator. The precision values in the table are for the individual determinations and were computed as follows:

$$
\% \text { Precision }= \pm \frac{\sigma}{\bar{x}} \times 100
$$

where $\sigma=$ best estimate of standard deviation

$$
\begin{aligned}
& \sigma=\sqrt{\frac{\sum(x-\bar{x})^{2}}{n-1}} \\
& \bar{x}=\text { average value }
\end{aligned}
$$

The deviations of the average found values from the standard value were tested by Student's " $t$ " test on the $99 \%$ confidence level, and are not significant.

In conjunction with some special problems, several other uranium standardis were analyzed. Table III gives the results of these analyses. The precision is calculated as above. The samples were prepared as follows: Carefully purified uranium nitrate hexahydrate was calcined to give the oxide. This oxide was analyzed by macro gravimetric and volumetric methods a large number of times to give the result shown as the accepted value. The $\mathrm{UO}_{2} \mathrm{Cl}_{2}$ solutions were made by taking weighed portions of the oxide and dissolving in dilute hydrochloric acid, using bromine to oxidize the uranium to (VI) state. The solutions were made up by weight to the value shown in the table. For the analysis, two uranium oxide samples of approximately $0.25 \mathrm{~g}$. each were dissolved in approximately $60 \mathrm{~g}$. of $3 \mathrm{M} \mathrm{HCl}$ with the aid of bromine. Three allquots of $0.5 \mathrm{~g}$. of each solution were analyzed, and the results combined to give the value in the table. For the $\mathrm{UO}_{2} \mathrm{Cl}_{2}$ (Solution I), the two samples were diluted $10: 1$ by weight, and $0.5 \mathrm{~g}$. samples of the dilution were taken as above. Six $0.5 \mathrm{~g}$. aliquots of the final solution were used. For all three standards the uranium titrated per sample was from 1 to $1.5 \mathrm{mg}$.

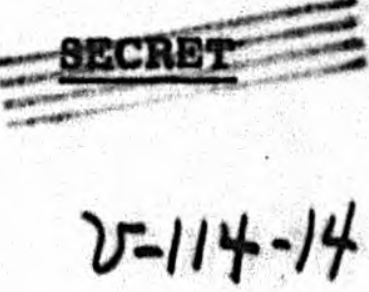




\section{TABLE III}

\section{ANALYSES OF STANDARD URANIUM SAMPLES}

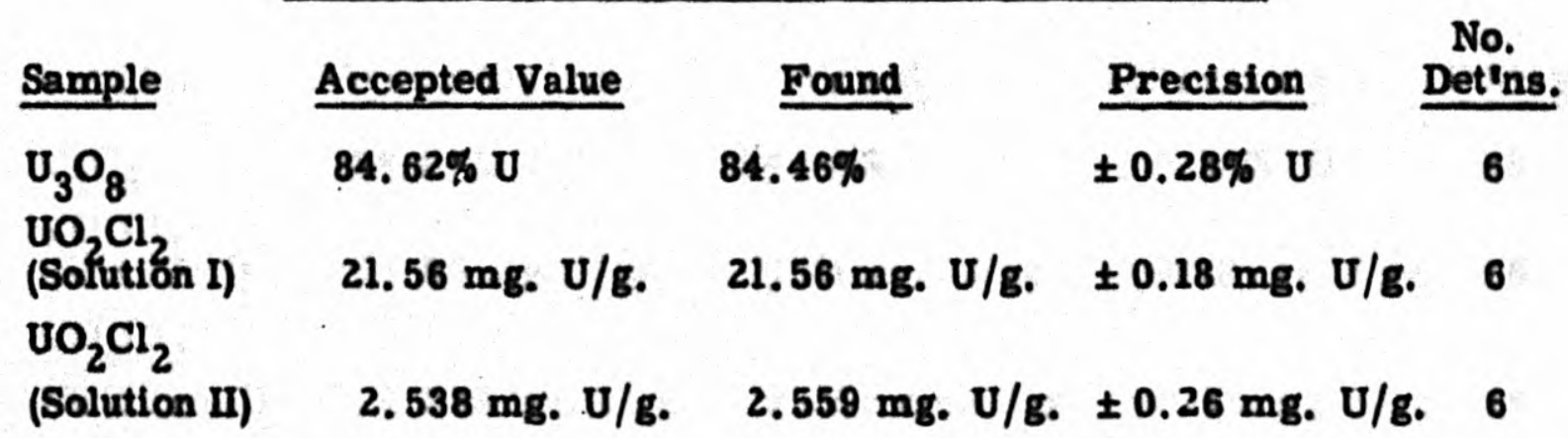

The method has been used in the analysis of some special samples, and the results are reported by E. M. Kinderman in another report (4). The method has also been used in the analysis of solutions of uranium as low as $10^{-5} \mathrm{M}$. The results are reported by $\mathrm{E}$. M. Kinderman in another report (5).

\section{DISCUSSION}

The differential polarographic indicator system usèd behaves as expected for the irreversible uranyl-uranous couple by developing a high potential at the start of the titration, which decreases sharply at the endpoint. The stoichiometric endpoint in our apparatus occurs at $175 \mathrm{mv}$. The endpoint shifts for different polarization currents and size of electrodes, but can be found definitely by titration in increments across the endpoint. The setting of the trigger cut-off potential at the endpoint is not critical, as a change in $\mathbf{5 0} \mathrm{mv}$. will not result in appreciable change in titration time.

During the development work on the method, a potentiometric indicator system, using calomel-platinum electrodes, was used. This was satisfactory insofar as behavior of the system was concerned, but

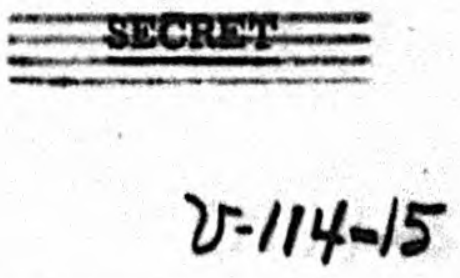


frequent failures of the calomel electrode were experienced, caused by the high temperature of operation. The endpoint potential in this system is $\mathbf{2 6 0} \mathrm{mv}$. This system would be usable if a reference electrode suitable for use in the hot acid solutions were developed.

Both the potentiometric and differential polarographic indicators show a marked anticipatory behavior. This is because the ferric iron generated does not react rapidly with the uranium, and a small excess concentration of ferric ion can be present during the titration. As stated previously, this behavior is an asset in making the titration automatic, as it prevents overtitration.

Ferric ion exists as a highly colored bromide complex in the titration media. The endpoint can be detected by observing the appearance of this dark color, if no other colored lons are present. This color formation is not suitable for precise work, however, for the appearance of a darkly colored solution at the end of a titration is a sign of overtitration, if the original solution is light in color.

The autotitrator used was set up in duplex, 1.e., two titration cells were used for one power supply. The operator can thus prepare a sample while the previous one is being titrated. Without undue exertion by the operator, 35-40 samples can be titrated per working day. This is in contrast to the average of $12-15$ per day when the titration is performed manually.

The primary difficulty in the method lies in the removal of interferences. Traces of nitrate, oxygen, and other oxidizing agents are not reduced by the lead reductor, but oxidize the iron in the hot hydrobromic acid medium, causing low results. Therufore, it is imperative that all samples which may have such traces of oxidants be pretreated by heating with hydrobromic acid before reduction.

The lead reductor is relatively unaffected by most forelgn ions, except in the case where the ion tends to be reduced and plated out. This 
is true of copper and tin. Phosphate, sulfate, and other anions which form insoluble lead salts cause no difficulties as long as the solutions are $3 \underline{M}$ in hydrobromic acid. The reductor tends to retain small amounts of uranium unless it is rinsed with a dilute iron solution. No retention is observed when the iron solution is $0.02 \mathrm{M}$ or above. Hot acid solutions make the reductor gas appreciably but do not affect its operation. Air does not cause peroxide formation as in the Jones reductor, so accidental admission of air to the column is not harmful.

The iron concentration affects the endpoint such that the lower the concentration the sharper the endpoint. The lower limit is set by the rinsing requirements. The potentiometric indicator system responds only to the ferric-ferrous couple. For the differential polarographic system the potential is also independent of uranium over a large range of concentration.

The method appears to be most useful in the titration of solutions of uranium which do not have impurities that are not removed by the simple pretreatment of boiling with an excess of acid or with free bromine. The wide range of concentrations that can be easily handled is also useful. Finally, the method is easily learned and relatively free of operator error.

\section{ACKNOWLEDGMENTS}

The author wishes to acknowledge the work on this method performed by some of his co-workers. These were D. J. Watkins, who did the precision studies, many of the interference studies, and helped in the differential polarographic endpoint studies; E. M. Kinderman, who helped with the pretreatment and interference studies and the early autoautic titrations; W. W. Mills, who furnished many of the standards for the investigation; and R. Ko and G. Meyer, who established the need for iron in the generation system.

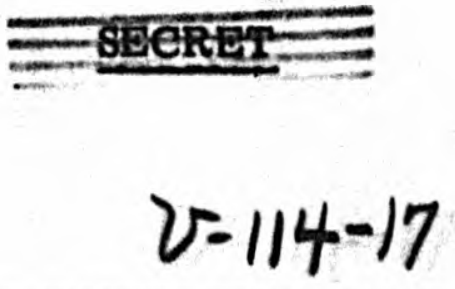




\section{BIBLIOGRAPHY}

(1) Carson, W. N., Jr., "An Automatic Titrator Using Electrolytically Generated Titrants, " HW-22780 (Secret).

(2) Carson, W. N., Jr. and Ko, R., Anal. Chem. 23, 1019 (1951).

(3) Cooke, W. D., Hazel, F., and McNabb, W. M. , Anal. Chem. 22, 654 (1950).

(4) Kinderman, E. M. , "Coulometric Method of Analysis Applied to Determination of Uranium in Aluminum-Uranium Solution," HW-22782 (Secret).

(5) Kinderman, E. M., "Determination of Uranium in AluminumSilicon Alloys," HW-22781 (Secret).

(6) Reilley, C. N., Cooke, W. D., and Furman, N. H., Anal. Chem. 22, 1223 (1951).

(7) Shaw, J. A., Ind. Engr. Chem. Anal. Ed. 6, 479 (1934).

(8) Shipley, E. D., AECD-2804.

WNC:dt
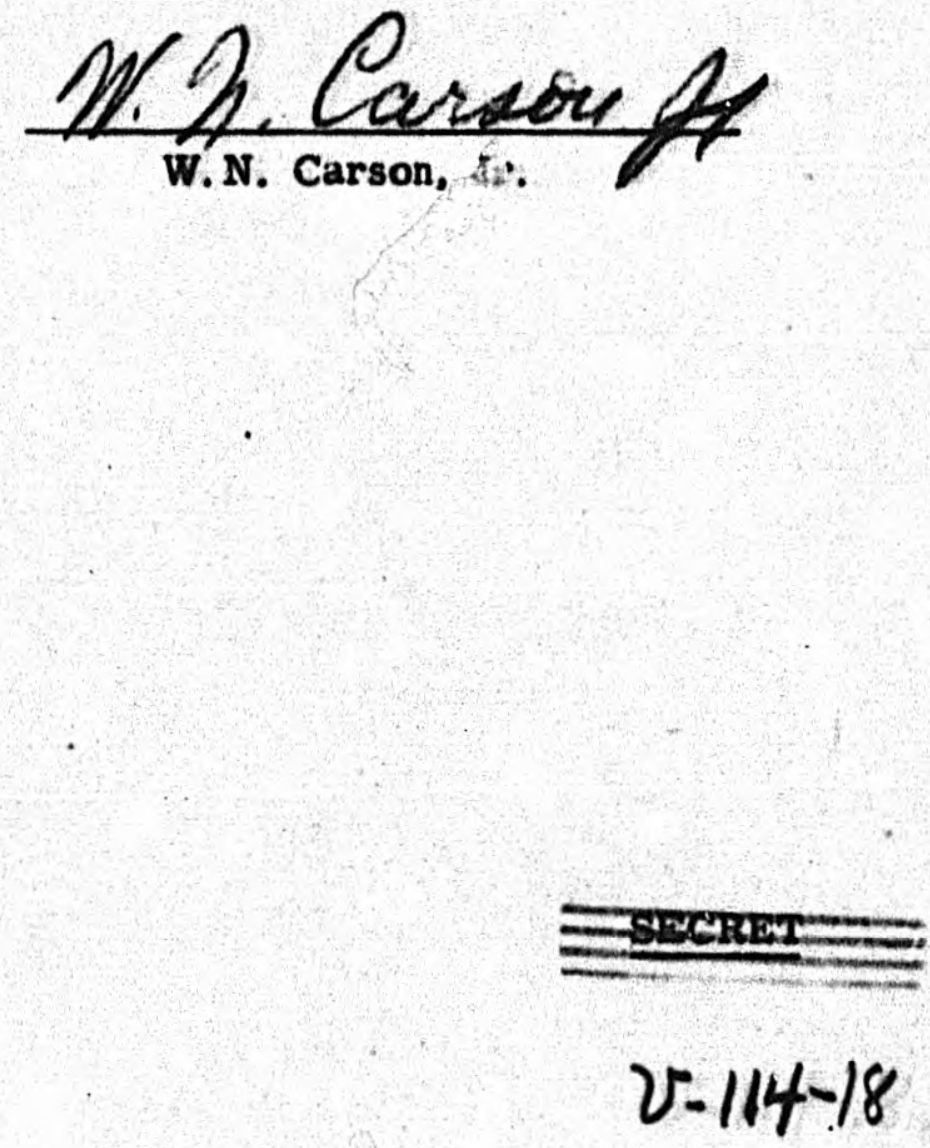


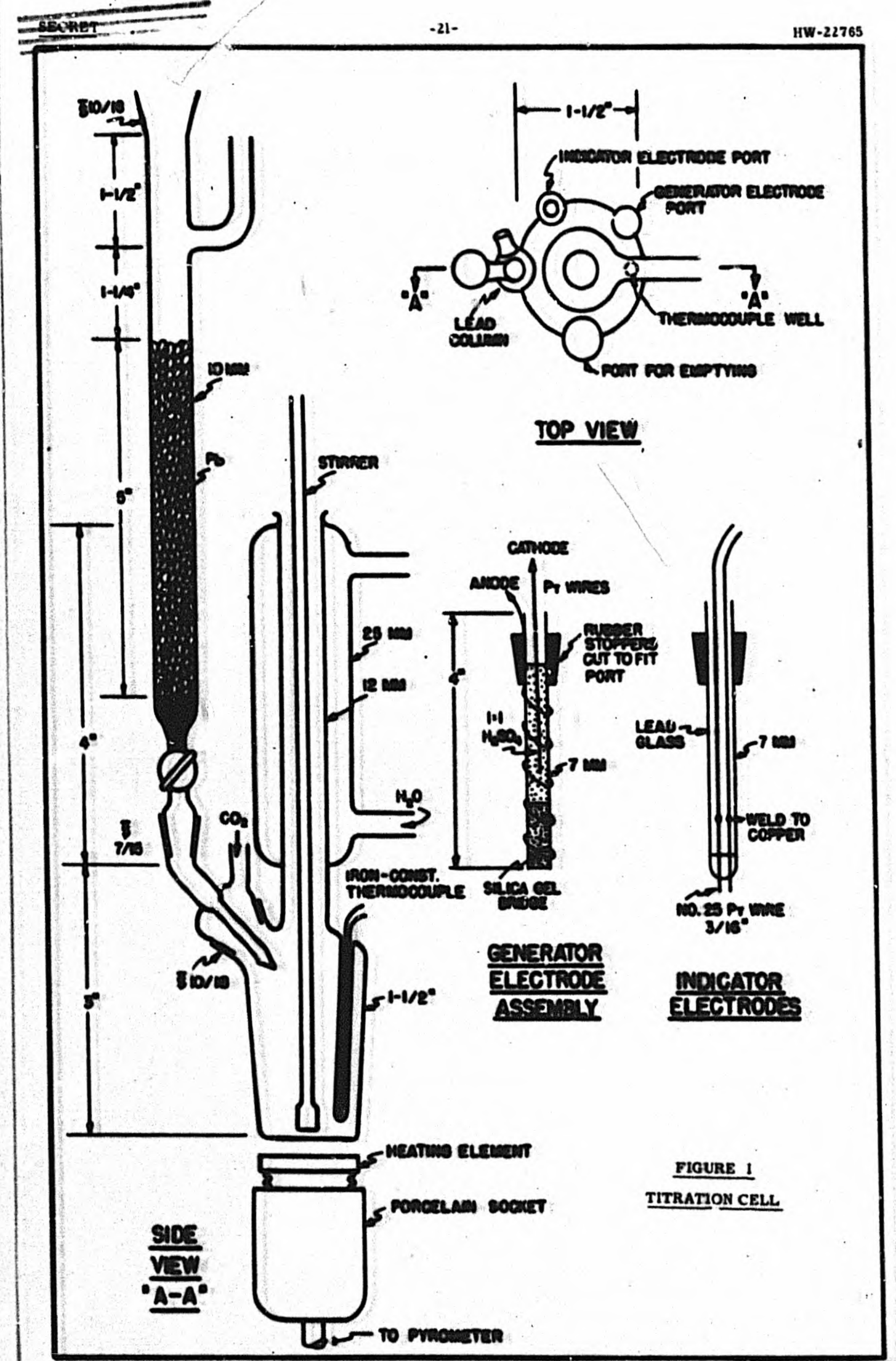




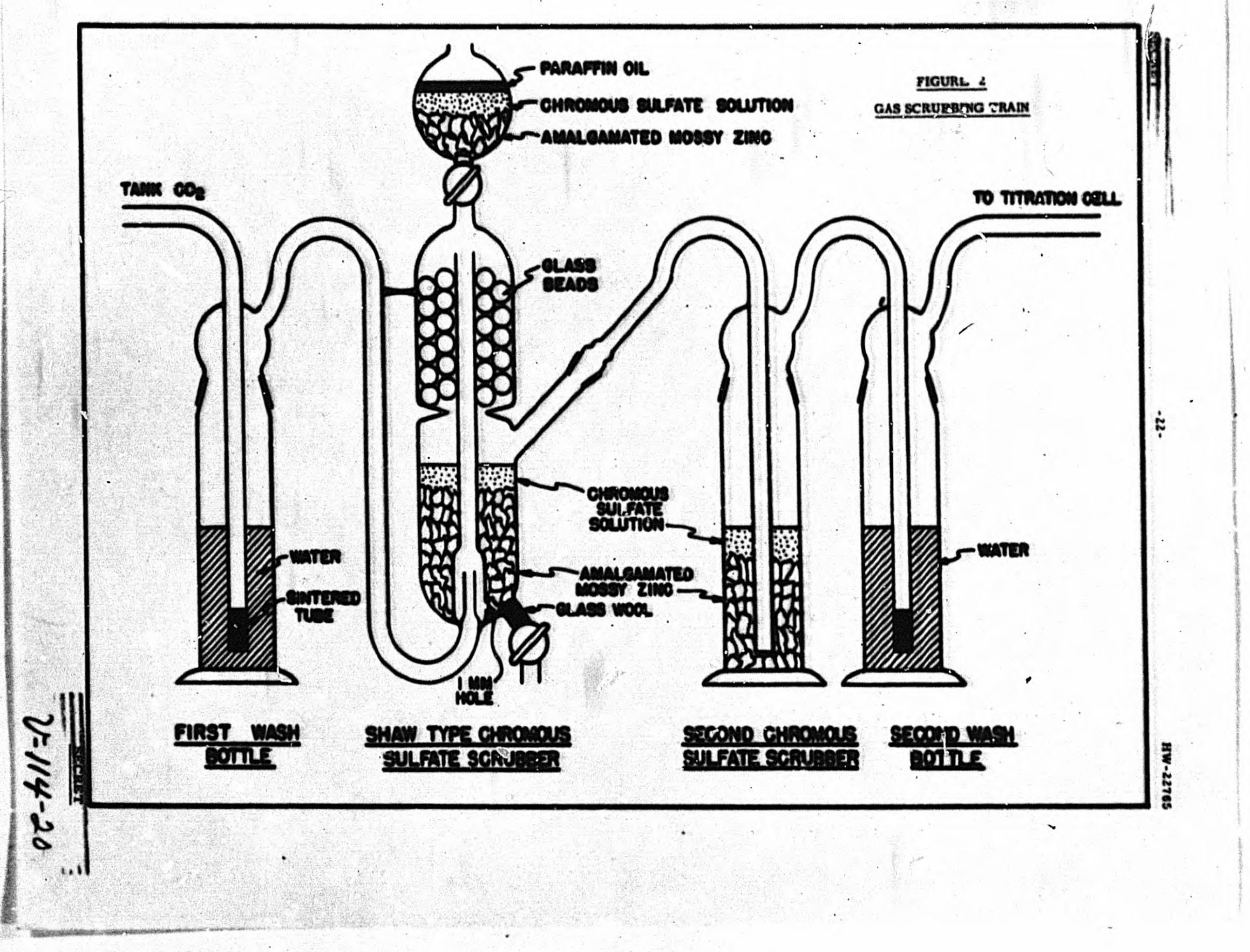




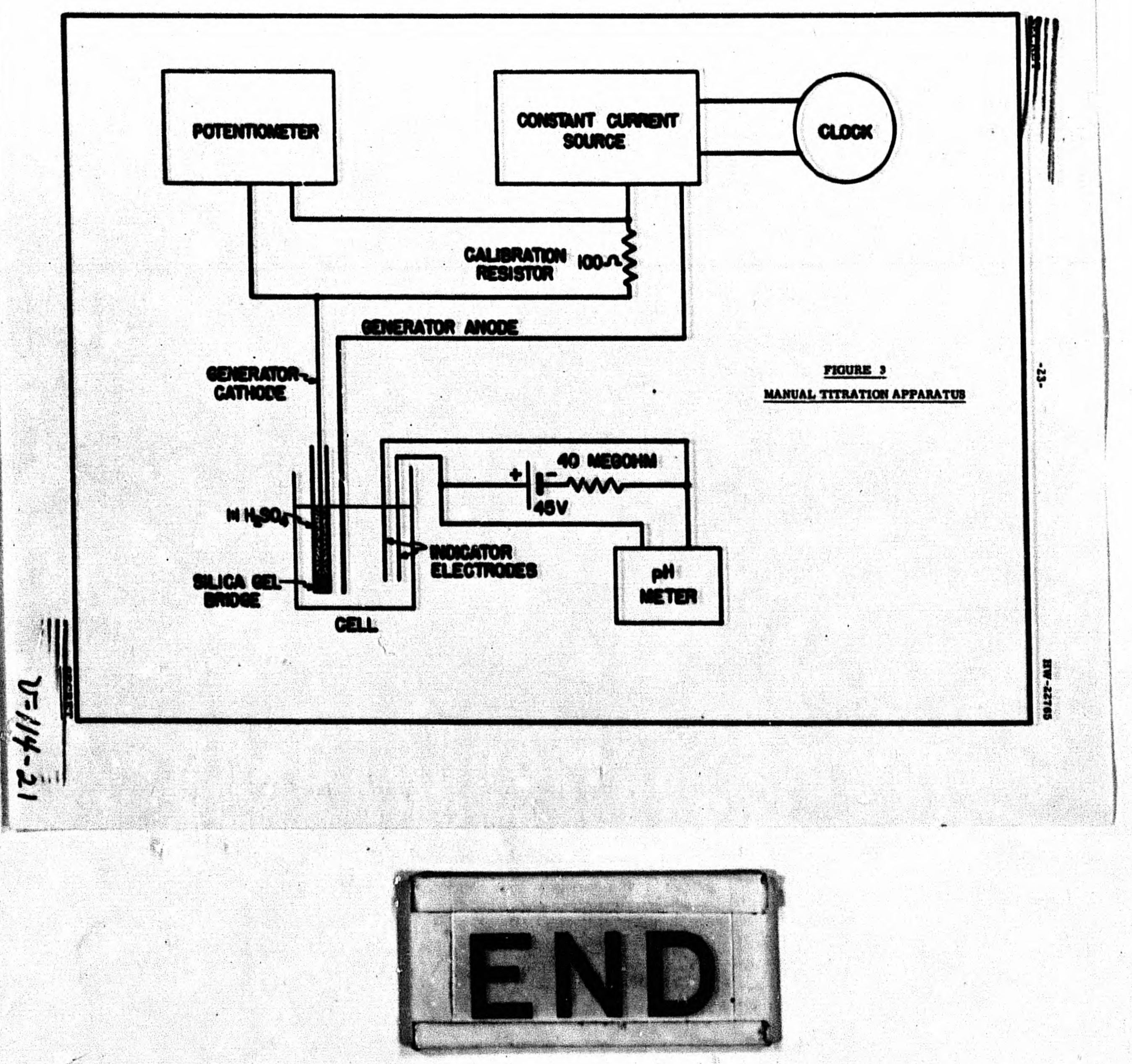

